\title{
Pathology and Therapeutics of COVID-19: A Review
}

Haleema Anwar, ', Qudsia Umaira Khan.²

\begin{abstract}
COVID-19 pandemic has taken over the world. Spreading from its epicenter in a seafood market in Wuhan, China to more than 200 countries, it has caused alarming situations. The viral infection is caused by an RNA virus called SARS-CoV-2. Its genome resembles the SARS-CoV-1 and MERS-COV genome. COVID19 cases were first reported in December 2019 in China, with infection causing a mild to severe respiratory disease. No antiviral drug for the infection has been shown to be effective, however many drugs are approved in the context of clinical trials. The review article will first present the structure of the SARS-COV- 2 and compare it to SARS-COV- 1 and MERS-CoV. The article will then highlight its effect on different organs. Finally, it will highlight the therapeutics which are in consideration and those which are being used.
\end{abstract}

Key Words: Pandemic; Phylogenetic Analysis; Differential Diagnosis; Incubation Period; Viral Genome (Source: MeSH-NLM).

\section{Introduction}

In December 2019, several cases of unexplained pneumonia appeared in Wuhan, China. The symptoms were like those caused by SARS-CoV (Severe Acute Respiratory Syndrome-Coronavirus) in 2003 which included cough, fever and fatigue. The infectious virus responsible for this was identified as SARS-COV-2 and the infection was called COVID19. Starting from its epicenter in China, COVID-19 has affected more than 200 countries. The virus mostly causes mild cases. The status of COVID-19 for the world at present is: total deaths 310,003 , total people recovered $1,780,118$, and total cases $4,670,224$ as on $16^{\text {th }}$ May $2020,4: 00$ pm GMT. ${ }^{1}$

COVID-19 was declared a 'global pandemic' on March 11, 2020 by the director general of the World Health Organization (WHO). ${ }^{2}$ This study aims to present the structure of the SARS-COV-2 and compare it to SARSCoV- 1 and MERS-CoV, highlight its effect on different organs, and the therapeutics which are in consideration and those which are being used. Information was extracted from PubMed and Google Scholar searches using keywords as: "COVID-19", "SARS-COV-2", and "Pandemic".

\section{Previous pandemics}

COVID-19 is not the only pandemic that has been experienced by the world. Coronaviruses have previously caused infectious outbreaks. These include SARS-COV and MERS-COV (Middle East respiratory syndrome-coronavirus). SARS-CoV was identified in 2003. It began in China causing approximately 8000 cases. MERS-CoV began in Saudi Arabia in 2012 and led to 2500 cases. ${ }^{3}$ Each virus caused an estimated 800 fatalities.

The measure of the infectiousness of the disease is of significance. It is depicted by a value called $R_{0}$ which is the number of secondary cases per case in a totally susceptible population. $R_{0}$ greater than 1 means that the case numbers will increase. A comparison of maximum and minimum $R_{0}$ for SARS-CoV-2 with other coronaviruses is shown in Figure 1 ; however, this value might change at the end of the pandemic. SARSCoV-1 has the highest Ro value. The seriousness and severity of the disease is measured by the case fatality. At present the case fatality of
SARS-COV-2 is $2 \%$ (i.e. 1 in 50 people with the disease will die). For MERS-COV it was thought to be $37 \%$ and for SARS-CoV it was $10 \% . .^{4}$ There may be discrepancies in the data because most of the COVID-19 patients are asymptomatic and therefore many patients may have not been tested.

Figure 1. Maximum and minimum $R_{0}$ value of the viruses.

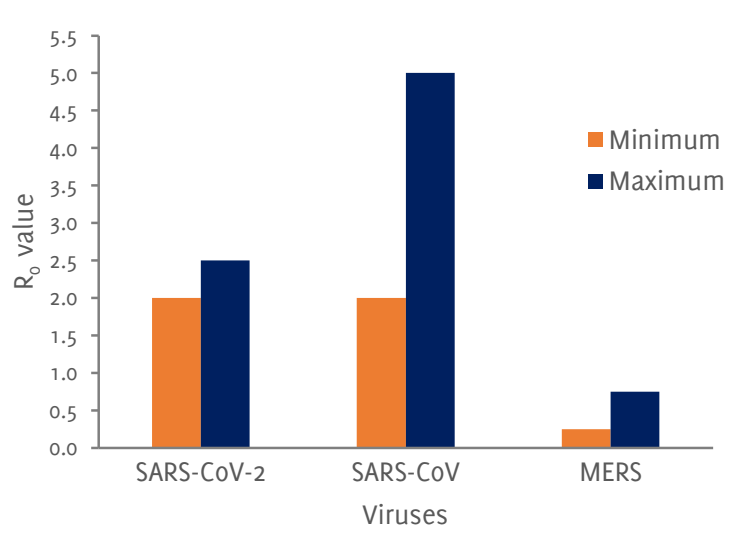

Structure of SARS-CoV-2

SARS-CoV-2, a member of the coronavirus family, is the name given to the causative agent of COVID-19 infection by International Virus Classification Commission. Coronaviruses have four known genera: Alphacoronavirus, Betacoronavirus, Gammacoronavirus, and Deltacoronavirus. Seven CoVs have been identified so far that may infect humans (HCOVs): two of which are alphacoronavirus (229E and $\mathrm{NL63}$ ) and the other are Betacoronavirus, or $\beta-\mathrm{CoV}$, (such as $0 \mathrm{C}_{43}$, HKU1, SARS-COV-2). ${ }^{3}$ SARS-COV- 2 has been classified as $\beta$-CoV. Corona is a Latin word which means 'crown', a name which was associated with the family because the surface projection on the viral envelope gives it such an appearance.

\footnotetext{
1 Medical student, CMH Lahore Medical College \& IOL, Lahore, Pakistan.

2 MBBS, M.Phil., FCPS II, CMH Lahore Medical College \& IOL, Lahore, Pakistan.
}

About the Author: Haleema Anwar is currently a 2nd year medical student of MBBS at CMH Lahore Medical and Dental College, Lahore, Pakistan of a 5-years medical program. She is enthusiastically involved in medical research to keep herself abreast with the current techniques and technologies being used in the field of medicine. She is very energetic in social work, presently selected as a Head of a team in a blood donating society of the college 'Cmh LMC lifeline'.

Correspondence:

Haleema Anwar

Address: Infantry Road, Abdul Rehman Rd, Sarwar Colony, Lahore, Punjab, Pakistan Email: haleemaa670@gmail.com
Editor: Francisco J. Bonilla-Escobar \& Mihnea-Alexandru Căman Student Editors: Paul MacDaragh Ryan 0 Madeleine Jemima Cox Submission: Apr 8,2020 Revisions required: April 27, 2020; May 16, 2020 Received in revised form: April 30, 2020; May 16, 2020 Acceptance: May 16, 2020 Publication: May 18, 2020 Process: Peer-reviewed 
CoVs are RNA enveloped viruses with nucleocapsid proteins and have a genome of around $30 \mathrm{~kb}$ in length, making them the largest known RNA viruses, with a diameter of approximately 60-140 nm. The SARSCoV-2 has ten Open Reading Frames (ORFs). ${ }^{4}$

The genomic structure has a $5^{\prime}$-cap structure and a $3^{\prime}$-poly-A tail and encodes for structural and non-structural proteins. The structure has mainly four structural proteins: spike (a glycoproteins composed of two subunits $S_{1}$ and S2$_{2}$ ) which helps the virus to attach to the host, membrane which help shape the virion particle, envelop which is involved in assembly and release of particle, and nucleocapsid which aids the binding of the genome to a replication transcription complex for the replication of its genetic material. ${ }^{5}$

Phylogenetic analysis revealed that SARS-CoV-2 is $80 \%$ and $50 \%$ identical to SARS-COV and MERS-COV, respectively (Figure 2). Similarly, both viruses were of bat origin. A single intact ORF was found on gene 8. This evidence points out that the possible origin of SARS-CoV-2 virus is from bats.

Figure 2. Genetic similarity of SARS-CoV-2 with other viruses.

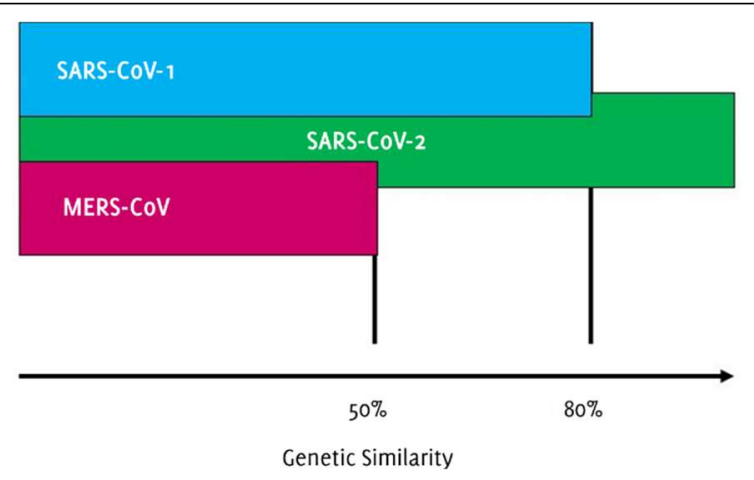

MERS-CoV uses dipeptidyl peptidase (DPP4) as a receptor whereas SARS-COV and SARS-COV-2 utilize ACE-2 (Angiotensin-Converting Enzyme-2) as their receptors, which is a membrane bound aminopeptidase. SARS-CoV-2 entry is dependent on protease, the most important of which being the employment of protease Transmembrane Serine Protease 2 (TMPRSS2) for priming of the viral S protein. This is of significance as TMPRSS2 activity is important for viral spread and pathogenesis. ${ }^{4}$ These receptors are under pharmacological considerations.

The incubation period of COVID-19 is calculated to have a median of 6.4 days. ${ }^{6}$ This gives information about how long it takes for a patient infected with SARS-CoV-2 to develop symptoms and forms the basis for a quarantine period. A longer incubation period signifies a higher rate of asymptomatic and subclinical infection in individuals who are immunologically competent. A comparison of three related viruses is shown in Figure 3, wherein we have chosen the maximum value of the period i.e. $2-7$ duration of SARS-CoV we selected 7. The virus is very infectious, and a study on familial group of five patients has revealed that asymptomatic carriers can transmit the infection to others even when the virus is in the incubation period.?

\section{Diagnosis and Pathology}

Various methods for the diagnosis of the infection are used. These include Real-Time quantitative Polymerase Chain Reaction (RT-qPCR), high-throughput sequencing, CT scan and immunological detection kits. These methods are shown in Table 1.

After the onset of the infection, the clinical manifestation ranged from asymptomatic patients to patients with septic shock. As the disease progresses, it may be categorized as mild, moderate, severe, or critical. $81 \%$ of the cases were mild. Cases critical in severity were reported to be $5 \% .{ }^{8}$ The case fatality rates of patients with chronic illnesses and patients of critical severity were high.
Figure 3. Incubation periods of the viruses.

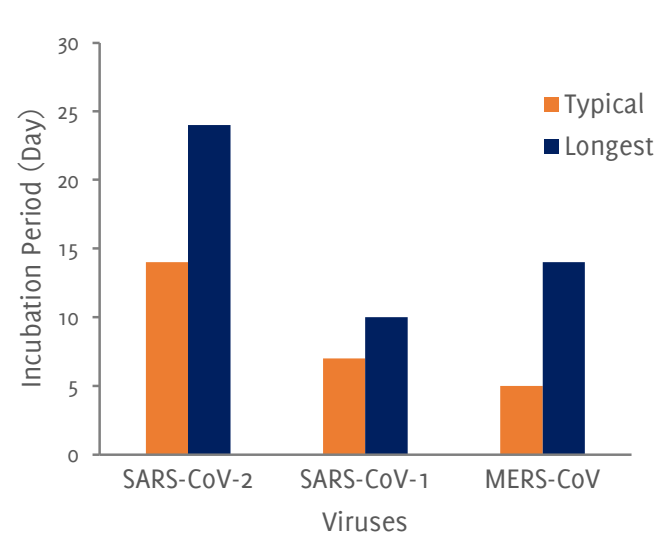

The following findings are laboratory features for early stage ICU patients and critical patients were the following. CD4 and CD8 lymphocytes were reduced in patients of early stage. Interleukin level (IL-2, IL-7, IL-10), granulocyte colony stimulating factor and tumor necrosis factor- $\alpha$ (TNF- $\alpha$ ) were high in intensive care unit patients. Amylase levels were high in critical patients. C-reactive protein (CRP) levels are directly proportional to disease severity and its progress. ${ }^{8}$ From pieces of evidence, it has been suggested that there is a subgroup of severe COVID-19 patients that might have cytokine storm syndrome. In this condition, there is an urgent need to reduce rising mortality by using approved, existing therapies and treatments of hyperinflammation with safety profiles and measures. The current method of managing and curing COVID-19 patients is supportive and protective. It has been investigated that the prime cause of death in COVID-19 patients is the respiratory failure that is due to acute respiratory distress syndrome (ARDS). Another syndrome that is characterized by sudden and severe fatal hypercytokinemia with the probability of multiorgan failure is secondary haemophagocytic lymphohistiocytosis (sHLH). It is a hyperinflammatory syndrome that is generally triggered by viral infections in adults and responsible for $3.7-4.3 \%$ of sepsis cases. Major features of SHLH are fever, hyperferritinanemia, cytopenia, and involves pulmonary system (ARDS) in $50 \%$ cases. Severe COVID- 19 disease has a cytokine profile resembling SHLH. It is characterized by an increased number of interleukins, monocytes, interferons, macrophages, inflammatory proteins, and TNF- $\alpha$. The study of 150 COVID-19 cases shows mortality from a recent retrospective study.., 10

SARS-CoV-2 stands for Severe Acute Respiratory Syndrome- Coronavirus 2. It is found to damage the lungs, but its effects are not limited to the lung tissue. Its influence on liver, central nervous system (CNS) and cardiovascular system (CVS) are under consideration. SARS-CoV-2 infects ciliated bronchial epithelial cells and type II pneumatocytes of lung tissue. ${ }^{11}$ In a study, biopsy samples were taken from the lung tissue. It showed desquamation of the pneumatocytes, hyaline membrane formation and pulmonary edema. All these findings are suggested of ARDS. In the intersitium, mononuclear inflammatory infiltrates were seen with lymphocyte predominance. The intra-alveolar space showed viral cytoplasmic-like changes, which included multinuclear syncytial cells with atypically enlarged pneumatocytes that had prominent nucleoli, large nuclei, and amphophilic granular cytoplasm. ${ }^{12}$ SARS-COV, SARS-CoV-2 and MERS-CoV infect a common cell, which is the type II pneumatocytes. MERS-CoV differed from the others in that it damaged the unciliated bronchial epithelial cells as compared the ciliated bronchial epithelial cell infected by SARS-COV and SARS-COV-2.

SARS-CoV-2 can directly bind to ACE 2 receptors on cholangiocytes leading to problems with the biliary system and secondary causing injury to the liver. This finding was in congruence with a study in which patients in the subclinical phase (that is before the onset of the symptoms) had lower aspartate aminotransferase (AST) level abnormalities than the patients who were diagnosed after the onset of 
Table 1. The various diagnostic methods used for detection of COVID-19.

\begin{tabular}{|c|c|}
\hline Diagnostic method & Efficiency and Limitations \\
\hline $\begin{array}{l}\text { RT-qPCR (Real-Time } \\
\text { quantitative } \\
\text { Polymerase Chain } \\
\text { Reaction) }\end{array}$ & $\begin{array}{l}\text { High sensitivity and specificity } \\
\text { Limitations: } \\
\text { - Long waiting time for result } \\
\text { - Can show false-negative result }\end{array}$ \\
\hline $\begin{array}{l}\text { High-throughput } \\
\text { sequencing }\end{array}$ & $\begin{array}{l}\text { Authoritative identification method } \\
\text { Limitations: } \\
\text { - High cost } \\
\text { - } \quad \text { Equipment dependency }\end{array}$ \\
\hline CT scan & $\begin{array}{l}\text { Has higher clinical diagnostic value for } \\
\text { COVID-19 } \\
\text { Limitations: } \\
\text { - Cannot distinguish between } \\
\text { pneumonia caused by COVID- } \\
\text { 19or another pathogen } \\
\text { - Hysteresis of abnormal CT } \\
\text { imaging }\end{array}$ \\
\hline $\begin{array}{l}\text { Immunological } \\
\text { detection kits }\end{array}$ & $\begin{array}{l}\text { ELISA kits have been developed and } \\
\text { pretested by some companies } \\
\text { SARS-CoV-2 N-based Ig G ELISA has higher } \\
\text { sensitivity than S- based Ig G ELISA. }\end{array}$ \\
\hline
\end{tabular}

the symptoms. ${ }^{8}$ Inflammation caused by immune activation (i.e. cytokine storm) can cause liver damage. Hypoxia due to respiratory syndrome causes lack of oxygen to the liver tissue contributing to liver dysfunction. In MERS-CoV, no viral particle was detected in liver tissue. ${ }^{13}$ There is an association of extreme severity of COVID-19 disease to a cytokine profile that resembles secondary haemophagocytic lymphohistiocytosis (SHLH). This is distinguished by increased IL-2, IL7. granulocyte colony-stimulating factor (GCSF), IFN (interferon)-y inducible protein 10 , monocyte chemoattractant protein (MCP) 1 , macrophage inflammatory protein (MIP) $1-\alpha$, and TNF- $\alpha .{ }^{14} \mathrm{~A}$ multicenter study (clinical research of multi-labs and clinics) of 150 confirm COVID-19 cases predicted fatality from some recent retrospective study. Hyper-inflammatory screening should be done, with the help of recent clinical-lab inventions, for the patients who suffer severe SARS-CoV-2 infection. The clinical techniques should keep a check on ferritin increase, decrease in platelet count, or erythrocyte sedimentation rate. Along with the screening, HScore 11 (patient's performance record table) should be used to distinguish the patients who can show transient improvement through immuno-suppression. Ingestion or intake of steroids, intravenous immunoglobulin, selective cytokine blockade, and JAK inhibition are some considerable curative options. ${ }^{15}$

The functional receptor of SARS-CoV-2 is ACE2. This receptor is present on different human tissue which include nervous tissue, skeletal muscle, cardiac tissue and liver tissue. In a study of 214 COVID-19 patients, it was revealed that these patients had neurological symptoms with PNS and CNS involvement. ${ }^{16}$ The symptoms were more pronounced in patients with severe infection of COVID-19. The symptoms were acute cerebrovascular disease and conscious disturbance. CNS symptoms included dizziness and headache. In comparison to other coronaviruses, neurological injury was confirmed in SARS-COV and MERS-COV. SARS-COV nucleic acid was detected in CSF and brain tissue biopsy of the patients. A case study supports the possibility of the COVID-19 causing neurological dysfunctions. A COVID19 infected 61-year-old women presented with acute weakness and severe fatigue of lower limbs. There was a decrease in sensation of light touch and pinprick. Laboratory findings revealed demyelinating neuropathy. She was diagnosed Guillain-Barré syndrome. This might suggest an association between SARS-COV-2 and Guillain-Barré syndrome because the starting point of Guillain-Barré syndrome overlapped with the duration of COVID-19 infection. ${ }^{16}$
ACE2 is highly expressed in lung and heart tissue. ${ }^{17}$ SARS-COV-2 enters the lung tissue via type II pneumatocytes. This viral entry causes downregulation of the ACE2 receptor which leads to accumulation of angiotensin II (Ang II) and reduced angiotensin-(1-7). Ang II-induced cardiac hypertrophy, fibrosis and infarction are the consequences of increased level of circulating Ang $11 .{ }^{13}$ Acute myocarditis and heart failure can also be caused by MERS-CoV. There is some mechanism by which heart injury is caused which includes hypoxemia complications, ACE2 related signaling pathways and an unbalanced response of two helper cells (type 1 and type 2 ) leading to cytokine storm. ${ }^{4}$ Figure 4 shows COVID-19 fatality rate by comorbidity.

Figure 4. COVID-19 Fatality Rate by Comorbidity. ${ }^{51}$

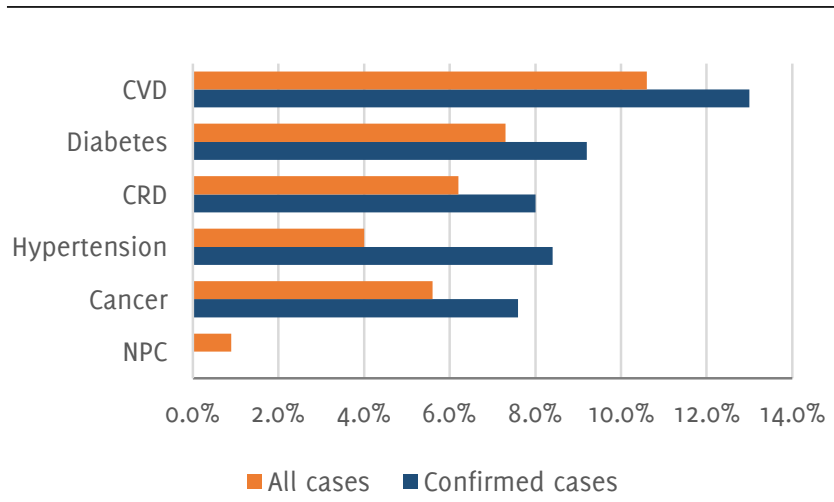

Legend: CVD, Cardiovascular disease; CRD, Chronic respiratory disease; NPC, No preexisting conditions.

In patients who had COVID-19 and sepsis various signs and symptoms were observed. Such symptoms include severe dyspnea and hypoxemia due to the damage to lungs, renal impairment and decreased urine output because of kidney damage, and tachycardia. ${ }^{3}$ There are certain cardiovascular complications due to viral infections that include myocarditis, heart failure, myocardial infarction of type 1 and 2, arrhythmias, pericarditis, and myocardial ischemia. COVID-19 is impacting many populations in the world. According to the current published data, many patients who are suffering from COVID-19 develop some cardiovascular complications. Almost $7 \%$ develop acute cardiac injuries, while $16 \%$ of the patients develop arrhythmia. Heart failure is caused in $23 \%$ of the COVID-19 patients. The reasons for heart failure are stress cardiomyopathy, new cardiomyopathy, and myocarditis. The new cardiomyopathy is related to the strong cytokine storm. Procoagulant activity, as well as systematic inflammatory response along with COVID-19, can increase the risk of acute myocardial infarction and cardiac injury. There may be a chance of myopericarditis, but it's rare. Some complications are associated with women only e.g. stress and cardiomyopathy. These are preceded by physical triggers or emotional triggers. Stress cardiomyopathy is usually associated with decreased left ventricular function as compared to the coronary syndrome. ${ }^{18,19}$

A cohort study of 41 patient confirmed with SARS-CoV-2 infection and admitted to a hospital in Wuhan, China reported clinical features of the infection. Certain features of the infection were like SARS-CoV and MERS-CoV which were fever, dry cough and dyspnea. ${ }^{4}$ Other similarities included: pneumonia, nonproductive cough, myalgia and fatigue. ${ }^{5}$ However, COVID-19 differed in that it showed apparent signs and symptoms of upper respiratory tract (e.g., rhinorrhea, sneezing or sore throat) and did not show intestinal signs and symptoms. MERS-CoV induced increased concentration of proinflammatory cytokines (IFN $Y$, TNF $\alpha$, IL 15, and IL 17)..$^{20}$ Patients infected with COVID-19 also had high amounts of IL1 $\beta$, IFN $Y$, IP10, and MCP1. COVID-19 differed from SARSCoV as COVID-19 caused an increase in secretion of T-helper-2 cytokines (e.g. IL4 and IL10).4

There are some complications due to COVID-19 that must be brought to light. These complications are ARDS, cytokine storm complicated with 
hemophagocytic syndrome, myocardial injury and coagulopathy. There is a high risk of venous thromboembolism. D-dimer might be helpful in early recognition of patients with high risk of such coagulations. ${ }^{21}$ In a study of 449 patients with severe COVID-19 who had sepsis-induced coagulopathy or elevated levels of D-dimer, anticoagulant therapy was given and the result showed a lowered mortality. They were treated with low molecular weight heparin (LMWH).22

Differential diagnosis is very important to give appropriate and timely treatment to the patient. It includes the possibility of an infectious or non-infectious respiratory disease. ${ }^{3}$ These disorders include common cold caused by rhinovirus, upper and lower respiratory disease by human metapneumovirus (hMPV) and pneumonia caused by influenza and parainfluenza. Investigations such as detection of antigens must be carried out to rule out the possibility of such diseases.

\section{Therapeutics}

There is no antiviral treatment that has been approved for COVID-19, however, certain approaches for the cure are under consideration.

The base-line treatment for the patient infected with SARS-COV-2 is symptomatic. Isolation of the individual is most effective and oxygen therapy is recommended. The measure taken to contain the epidemic is quarantine because the virus is transmitted by human to human contact and physical contact with surfaces (i.e. cardboard, copper, stainless steel, plastic). Zoonotic transmission has also been stated. Drug intervention includes antiviral, antibacterial and antimalarial drugs.

As the virus affects the lungs, the major therapy for the infection is oxygen therapy. One of the preferred strategies is the endotracheal tube. It is recommended in patients with critical respiratory conditions. A waveform capnograph monitoring device should be used. This gives information about correct placement of endotracheal tubes and gives an idea about the extent of seal adequacy. High-flow nasal oxygen (HFNO) or non-invasive ventilation (NIV) improve oxygenation and lower the work of breathing but are not recommended for the treatment as they produce aerosol and the virus can be aerosolized. Their use is discouraged universally unless an airborne infection isolation room is accessible, or the patient has viral clearance. ${ }^{23}$

Studies have revealed that chloroquine has antiviral activity against RNA viruses in vitro. Several mechanisms by which this drug works is proposed. It might be due to interference of chloroquine with ACE 2 receptor glycosylation which prevents its attachment to the host cell. Chloroquine can work indirectly by reducing pro-inflammatory cytokines. A preliminary study indicated that the drug interferes with SARS-CoV-2 attempt to acidify lysosome, thus it works by increasing endosomal $\mathrm{pH}^{24}$

Remdesivir is an antiviral prodrug. It has been tested in animal model (i.e. mice), the test revealed that the drug reduced viral load in SARSCoV-2 infected mice. Remdesivir was used in three patients with severe disease. In one patient it was discontinued after 5 days because of ALT elevation. There was no confirmation whether this elevation was due to Remdesivir. A patient of renal replacement therapy was given only one dose and then Remdesivir was discontinued because it contained cyclodextrin (which is nephrotoxic). ${ }^{25}$ According to a placebo-controlled, multicenter trial for Remdesivir in ten hospitals in China, the drug did not show significant reduction in mortality or time to clearance of virus in seriously ill patients as compared with placebo group. A reduction in time of recovery was observed in patients who were treated earlier. ${ }^{26}$ Although there is inadequate knowledge about the safety and effectiveness of Remdesivir, the drug has been shown to shorten the time of recovery in some COVID-19 patients. It has been authorized for emergency use by FDA.

Many biopharmaceutical companies are aiming to develop prophylactic vaccines for the virus. These attempts are being made using DNA, mRNA and adenovirus vectors as platforms. The most advanced platform is DNA. Due to technological improvement, mRNA vaccines are more stable and have high efficiency for protein translation. These properties
Table 2. A list of recommended drugs with their properties and possible mechanism of action.

\begin{tabular}{|c|c|c|}
\hline Drug & Type & Properties and mechanism of action \\
\hline Chloroquine & Antimalarial & $\begin{array}{l}\text { Pharmacokinetics: } \\
\text { Reaches maximum plasma } \\
\text { level in } 3 \text { hours } \\
\text { Principally excreted by } \\
\text { kidney with initial half-life of } \\
\text { 3-5 days and terminal half- } \\
\text { life of } 1-2 \text { months } \\
\text { Mechanism: } \\
\text { Halts pH-dependent entry of } \\
\text { virus by altering pH of } \\
\text { endosome. Therefore, viral } \\
\text { genome is not released in } \\
\text { the cytosol because the viral } \\
\text { and endosomal membrane } \\
\text { fail to fuse. } \\
\text { It interferes with sialic acid } \\
\text { biosynthesis. Sialic acid } \\
\text { forms a complex with protein } \\
\text { capsid of virus that interact } \\
\text { with cell surface receptor of } \\
\text { human cell }\end{array}$ \\
\hline
\end{tabular}

\section{Kaletra}

(Lopinavir Antiviral Inhibitor of cytochrome P450 3A.

and

ritonavir)

\begin{tabular}{|c|c|c|}
\hline Ivermectin & $\begin{array}{l}\text { Anti- } \\
\text { parasitic }\end{array}$ & $\begin{array}{l}\text { Single dose controls viral replication } \\
\text { in } 24-48 \text { hours } \\
\text { A hypnotised mechanism of action is } \\
\text { by inhibition of nuclear import of } \\
\text { viral protein by the drug. }\end{array}$ \\
\hline Remdesivir & Antiviral & $\begin{array}{l}\text { It inhibits viral RNA polymerase, } \\
\text { thus prevents viral multiplication }\end{array}$ \\
\hline Teicoplanin & Antibiotic & $\begin{array}{l}\text { Used for treatment of gram-positive } \\
\text { bacteria } \\
\text { Inhibits cleavage of viral spike } \\
\text { protein at low pH by Cathepsin L. }\end{array}$ \\
\hline
\end{tabular}

induce a strong immune response. ${ }^{27}$ Table 2 shows a list of recommended drugs for the COVID-19.

An expert consensus recommended chloroquine phosphate tablets (500 mg twice per day for 10 days) for mild to severely infected patients. ${ }^{24}$ Certain precautions were also highlighted. These were blood testing, routine electrocardiography, administration of antiarrhythmic, antidepressant and antipsychotic drugs. Their precautions were recommended to exclude the possibility of anemia, thrombocytopenia or leukopenia, electrolyte disturbances, QT interval prolongation or bradycardia.

Dutch Center of Disease control suggested the need to stop treatment with chloroquine (CQ) at day five as the drug has a long half-life and can cause side effects. It also highlighted the need to differentiate between regimens based on chloroquine phosphate and chloroquine base. Italian scientists have recommended the utilization of Chloroquine or Hydroxychloroquine (HCQ) for patients with mild to severe respiratory symptoms. ${ }^{24}$ The use of $\mathrm{CQ}$ and HCQ is still controversial due to low clinical study at present.

CQ is largely being considered for the treatment for COVID-19. A study was carried out in Manaus, Brazilian Amazon to test the dosage of the drug. CQ was given orally or by nasogastric tube. High dose was given 
to one group (i.e. a total dose of $12 \mathrm{~g}$ over a period of 10 days) and low dosage was given to another group (i.e. a total dose of $2.7 \mathrm{~g}$ for 5 days). The results were against the use of high dose because it raised safety concerns. ${ }^{8}$

To determine the efficiency of HCQ, a study was conducted in Renim Hospital of Wuhan on 62 patients. The result showed a decrease in time to clinical recovery and cough remission time. Resolution of consolidation in pneumonia was also noted. This favors the use of HCQ under managed circumstances. A large-scale research study is still required for absolute support of the use of HCQ on a large scale. ${ }^{28}$

Two lead compounds have been designed $11 \mathrm{a}$ and $11 \mathrm{~b}$. These lead compounds bind to Cysi45 of $\mathrm{M}^{\text {pro }}$ (a protease used by the virus for entry into cells) via the aldehyde group. Trials were conducted in mice which revealed that $11 \mathrm{~b}$ has shorter half-life and faster clearance than 11a. 11a showed lower toxicity. Thus, the pharmacokinetic (PK) properties indicate that these are good candidates for treatment of SARS-COV-2. ${ }^{29}$ As TMPRSS2 (Transmembrane Serine Protease 2), an enzyme, is used for viral entry, an inhibitor to TMPRSS2 (such as camostat mesylate) can block the infection. Interferons inhibit replication of SARS-CoV-2 in vitro. The effectiveness of interferon $\beta$, interferon $\alpha$ and interferon $\gamma$ was studied. The result showed that interferon $\beta$ was most potent amongst all of them. Thus, interferon $\beta$ could be a drug used for treating the COVID-19.30

Some promising therapies are Remdesivir, vaccine, plasma therapy and stem-cell transfusion. Convalescent plasma has been used to treat previous outbreak like Ebola and MERS-CoV. This immunoglobulin treatment is understudy for COVID-19 because it blocks infection and suppresses viremia. ${ }^{31}$

Trial for vaccine development are accelerating. The aim is to device a vaccine which will be suitable for stocking for future use, suitable for adult health care workers and adults with underlining hypertension and diabetes. The major vaccines that have been established are whole virus vaccine, subunit vaccines and nucleic acid vaccine. ${ }^{32}$

Various companies and universities around the globe are working to develop the vaccine for COVID-19. At present, more than 90 vaccines have been designed. ${ }^{33}$ The vaccine presents antigen to the body to induce immunity to combat the infection when a person is infected. The type of vaccines being used are virus vaccine, viral vector vaccine, nucleic acid vaccine and protein-based vaccine, as shown in Table 3.

Convalescent plasma (CP) therapy is also being considered as a treatment because it has shown to decrease serum cytokine response. This is of great importance as viremia reaches its peak in the first week after infection and in the second week after onset of symptoms there is a cytokine storm which could prove to be life threatening. ${ }^{34}$ SARS CoV-2 induces a cytokine storm in the patients and CP therapy might be the gate way to improve this condition. CP has its limitations as it causes adverse results like chills, fever, anaphylactic reactions, transfusion-related acute lung injury, circulatory overload and hemolysis. 35

For the limitation of onward spread of the virus between individuals to contain the epidemic and slow its progression, WHO and othe organizations have given some recommendation for the prevention of spread of the infection. These recommendations include staying away from subjects who have acute respiratory infections, washing hands regularly, covering coughs or sneezes. Public gathering must be avoided especially by subjects with a compromised immune system.

\section{Discussion}

This article has led to the finding that coronavirus outbreaks have occurred before. This outbreak is unique due to the extent of emergency situations it has caused around the world. SARS-CoV- 2 does hold certain similarities with MERS-COV and SARS-COV in terms of genetics, receptor (i.e. ACE2 receptor used by SARS-COV and SARS-CoV- 2)
Table 3. Current state of COVID-19 vaccines.

\begin{tabular}{|c|c|c|}
\hline Vaccine & Type & Trials \\
\hline \multirow{7}{*}{$\begin{array}{l}\text { Virus } \\
\text { Vaccine }\end{array}$} & 1.Weakened & Codagenix \\
\hline & $\begin{array}{l}\text { Mutations are introduced } \\
\text { in the virus by passing it }\end{array}$ & $\begin{array}{l}\text { Farmingdale, New York, } \\
\text { and Serum Institute of }\end{array}$ \\
\hline & through animal and & India are working in \\
\hline & human cells to decrease & collaboration to \\
\hline & its infectiousness & $\begin{array}{l}\text { weaken the virus by } \\
\text { changing the genetic } \\
\text { code. }\end{array}$ \\
\hline & 2.Inactivated & Sinovac Biotech \\
\hline & $\begin{array}{l}\text { Chemicals or heat is used } \\
\text { to make the virus } \\
\text { infectious }\end{array}$ & $\begin{array}{l}\text { Beijing has started to } \\
\text { test an inactivated } \\
\text { version of SARS-CoV-2 } \\
\text { in humans }\end{array}$ \\
\hline
\end{tabular}

1.Replicating viral vector: A virus is genetically Viral vector modified so that it does Vaccine not cause disease. This type replicates in the cells.

2.Non-replicating viral vector: These are also genetically engineered but do not replicate because the key gene has been disabled

$\begin{array}{ll}\text { Protein } & \text { 1.Protein subunits: } \\ \text { based } & \text { Coronavirus proteins are } \\ \text { Vaccine } & \text { directly injected into the } \\ & \text { body. This includes the } \\ & \text { use of the virus spike } \\ & \text { protein or other key part. } \\ & \text { 2.Virus-like particles: } \\ & \text { These are empty virus } \\ & \text { without the genetic } \\ & \text { material and thus are not } \\ & \text { infectious. } \\ \text { Nucleic acid } & \text { 1.DNA-based vaccine: } \\ \text { vaccine } & \text { conetic code for } \\ & \text { injected in form of DNA. } \\ & \text { 2.RNA-based vaccine: RNA } \\ & \text { is used as genetic } \\ & \text { instruction } \\ & \text { coronavirus protein. for } \\ & \text { Typically, the spike } \\ \text { protein is encoded. }\end{array}$

US-based drug giant Johnson at Johnson is working on Nonreplicating viral vaccine

At present 28 teams are working on vaccines with viral protein subunits.

5 teams are working on 'virus-like particle' (VLP) vaccines.

20 teams are aiming to use this technique

and some symptoms. $R_{0}$, case fatality and incubation periods are distinctive for SARS-CoV- 2. This information is of importance because it serves as a pioneer for the establishment of treatment.

The study has limitations in terms of the time it has been done in because the pandemic has not been contained yet. Thus, some conclusions drawn from clinical trials and tests may change in future due to a better understanding on the grounds of the latest research.

The pandemic has posed obstacles in many aspects including economic, environmental, and psychological aspects. The most significant obstacle, at present, is its treatment because it is a certain tool to eradicate the COVID-19 infection and subsequently all problems that are arising due to it will settle down (especially the issue of economic crisis). Studies support that the best treatment is quarantine. The absolute treatment for the infection will take time and a great deal of future research.

The review has emphasized the virology, pathology and therapeutics of the most recent pandemic COVID-19. The pandemic is still escalating. It 


\section{Review}

is evident from the literature that the effect of this viral infection is not only bound to the lungs but is also harming other systems of the body. The exact mechanism about how COVID-19 is associated with certain disorders (such as neurological and cardiac) still require further research. This explains the complexity of the disease itself and difficulty for the search for its cure. At this point of the pandemic, there are an appreciable number of drugs and other therapeutic methods that have been researched but the absolute treatment is still to be achieved. Continuous development and research are underway to form a promising medication. Especially work is being done to design a vaccine for the infection and the latest research is pointing towards a promising result. 


\section{References}

1. Johns Hopkins University. https://coronavirus.jhu.edu/map.html. Cited May 16, 2020.

2. WHO Director-General's opening remarks at the media briefing on COVID19 March 2020, 2020

3. Rothan HA, Byrareddy SN. The epidemiology and pathogenesis of coronavirus disease (COVID-19) outbreak. J Autoimmun. 2020 May;109:102433.

4. Huang C, Wang Y, Li X, Ren L, Zhao J, Hu Y, et al. Clinical features of patients infected with 2019 novel coronavirus in Wuhan, China. Lancet. 2020 Feb 15;395(10223):497-506

5. Seah I, Agrawal R. Can the Coronavirus Disease 2019 (COVID-19) Affect the Eyes? A Review of Coronaviruses and Ocular Implications in Humans and Animals. Ocul Immunol Inflamm. 2020 Apr 2;28(3):391-395

6. Jiang X, Rayner S, Luo MH. Does SARS-CoV-2 has a longer incubation period than SARS and MERS? J Med Virol. 2020 May;92(5):476-478.

7. Ye F, Xu S, Rong Z, Xu R, Liu X, Deng P, Liu H, Xu X. Delivery of infection from asymptomatic carriers of COVID-19 in a familial cluster. Int J Infect Dis. 2020 May;94:133-138.

8. Borba M, de Almeida Val F, Sampaio VS, Alexandre MA, Melo GC, Brito M, et al. Chloroquine diphosphate in two different dosages as adjunctive therapy of hospitalized patients with severe respiratory syndrome in the context of coronavirus (SARS-CoV-2) infection: Preliminary safety results of a randomized, double-blinded, phase Ilb clinical trial (CloroCovid-19 Study). MedRxiv. 2020 Jan 1.

9. Mehta P, McAuley DF, Brown M, Sanchez E, Tattersall RS, Manson JJ; HLH Across Speciality Collaboration, UK. COVID-19: consider cytokine storm syndromes and immunosuppression. Lancet. 2020 Mar 28;395(10229):1033-1034.

10. Tay MZ, Poh CM, Rénia L, MacAry PA, Ng LFP. The trinity of COVID-19: immunity inflammation and intervention. Nat Rev Immunol. 2020 Jun;20(6):363-374.

11. Cui J, Li F, Shi ZL. Origin and evolution of pathogenic coronaviruses. Nat Rev Microbiol. 2019 Mar;17(3):181-192

12. $\mathrm{Xu} \mathrm{Z}$, Shi L, Wang $\mathrm{Y}$, Zhang J, Huang L, Zhang C, et al. Pathological findings of COVID-19 associated with acute respiratory distress syndrome. Lancet Respir Med. 2020 Apr;8(4):420-422

13. Vaduganathan $M$, Vardeny 0 , Michel T, McMurray JJV, Pfeffer MA, Solomon SD. Renin-Angiotensin-Aldosterone System Inhibitors in Patients with Covid-19. N Engl J Med. 2020 Apr 23;382(17):1653-1659.

14. Cui J, Li F, Shi ZL. Origin and evolution of pathogenic coronaviruses. Nat Rev Microbiol. 2019 Mar;17(3):181-192

15. Mehta P, McAuley DF, Brown M, Sanchez E, Tattersall RS, Manson JJ; HLH Across Speciality Collaboration, UK. COVID-19: consider cytokine storm syndromes and immunosuppression. Lancet. 2020 Mar 28;395(10229):1033-1034.

16. Zhao H, Shen D, Zhou H, Liu J, Chen S. Guillain-Barré syndrome associated with SARS-CoV-2 infection: causality or coincidence? Lancet Neurol. 2020 May; $19(5): 383-384$

17. Zheng YY, Ma YT, Zhang JY, Xie X. COVID-19 and the cardiovascular system. Nat Rev Cardiol. 2020 May; 17(5):259-260

18. Minhas AS, Scheel P, Garibaldi B, Liu G, Horton M, Jennings M, et al. Takotsubo Syndrome in the Setting of COVID-19. JACC Case Rep. 2020 Jul 15;2(9):1321-1325.
19. Zhou R. Does SARS-CoV-2 cause viral myocarditis in COVID-19 patients? Eur Heart J. 2020 Jun $7 ; 41(22): 2123$

20. Mahallawi WH, Khabour OF, Zhang Q, Makhdoum HM, Suliman BA. MERS-COV infection in humans is associated with a pro-inflammatory Th1 and Th17 cytokine profile. Cytokine. 2018 Apr;104:8-13

21. Kollias A, Kyriakoulis KG, Dimakakos E, Poulakou G, Stergiou CS, Syrigos K. Thromboembolic risk and anticoagulant therapy in COVID-19 patients: emerging evidence and call for action. Br J Haematol. 2020 Jun;189(5):846-847

22. Tang N, Bai H, Chen X, Cong J, Li D, Sun Z. Anticoagulant treatment is associated with decreased mortality in severe coronavirus disease 2019 patients with coagulopathy. J Thromb Haemost. 2020 May;18(5):1094-1099.

23. Cheung JC, Ho LT, Cheng JV, Cham EYK, Lam KN. Staff safety during emergency airway management for COVID-19 in Hong Kong. Lancet Respir Med. 2020 Apr;8(4):e19.

24. Cortegiani A, Ingoglia G, Ippolito M, Giarratano A, Einav S. A systematic review on the efficacy and safety of chloroquine for the treatment of COVID-19. J Crit Care. 2020 Jun;57:279-283.

25. Lescure FX, Bouadma L, Nguyen D, Parisey M, Wicky PH, Behillil S, et al. Clinical and virological data of the first cases of COVID-19 in Europe: a case series. Lancet Infect Dis. 2020 Jun;20(6):697-706.

26. Wang $Y$, Zhang D, Du G, Du R, Zhao J, Jin Y, et al. Remdesivir in adults with severe COVID-19: a randomised, double-blind, placebo-controlled, multicentre trial. Lancet. 2020 May 16;395(10236):1569-1578

27. Prompetchara E, Ketloy C, Palaga T. Immune responses in COVID-19 and potential vaccines: Lessons learned from SARS and MERS epidemic. Asian Pac J Allergy Immunol. 2020 Mar;38(1):1-9

28. Chen Z, Hu J, Zhang Z, Jiang S, Han S, Yan D, Zhuang R, Hu B, Zhang Z. Efficacy of hydroxychloroquine in patients with COVID-19: results of a randomized clinical trial. MedRxiv. 2020 Jan 1.

29. Dai W, Zhang B, Jiang XM, Su H, Li J, Zhao Y, et al. Structure-based design of antiviral drug candidates targeting the SARS-CoV-2 main protease. Science. 2020 Jun 19;368(6497):1331-1335

30. Devaux CA, Rolain JM, Colson P, Raoult D. New insights on the antiviral effects of chloroquine against coronavirus: what to expect for COVID-19? Int J Antimicrob Agents. 2020 May;55(5):105938.

31. Chen L, Xiong J, Bao L, Shi Y. Convalescent plasma as a potential therapy for COVID-19. Lancet Infect Dis. 2020 Apr;20(4):398-400.

32. Chen WH, Strych U, Hotez PJ, Bottazzi ME. The SARS-CoV-2 Vaccine Pipeline: an Overview. Curr Trop Med Rep. 2020 Mar 3:1-4.

33. Callaway E. The race for coronavirus vaccines: a graphical guide. Nature. 2020 Apr; $580(7805): 576-577$

34. Cheng $\mathrm{Y}$, Wong R, Soo Yo, Wong WS, Lee $\mathrm{CK}, \mathrm{Ng} \mathrm{MH}$, et al. Use of convalescent plasma therapy in SARS patients in Hong Kong. Eur J Clin Microbiol Infect Dis. 2005 Jan;24(1):44-6.

35. Zhao Q, He Y. Challenges of Convalescent Plasma Therapy on CoVID-19. J Clin Virol. 2020 Jun;127:104358. 


\section{Review}

\section{Acknowledgments}

None.

Conflict of Interest Statement at Funding

The Authors have no funding, financial relationships or conflicts of interest to disclose.

\section{Author Contributions}

Visualization: HA. Supervision: QUK. Writing - Original Draft: HA. Writing - Review a Editing: HA \& QUK.

Cite as:

Anwar H, Khan QU. Pathology and Therapeutics of COVID-19: A Review. Int J Med Students. 2020 May-Aug;8(2):113-120

This work is licensed under a Creative Commons Attribution 4.0 International License 